(REVIEW ARTICLE)

\title{
COVID-19 challenges: The Gambia situation and probable solutions
}

\author{
Tobiloba Oyejide Alex Omotosho 1, 3, ${ }^{*}$, Oluwatomilayo Felicity Omotosho ${ }^{1}$, Paul Bass 2 and Yahya Njie 3 \\ ${ }^{1}$ Department of Nursing and Reproductive Health, School of Medicine and Allied Health Sciences, University of the \\ Gambia, Banjul Campus, The Gambia, PO Box 1646, Banjul. \\ 2 Department of Public and Environmental Health, School of Medicine and Allied Health Sciences, University of the \\ Gambia, Brikama Campus, The Gambia, PO Box 3530, Serrekunda. \\ ${ }^{3}$ Edward Francis Small Teaching Hospital, Independence Drive, Banjul, The Gambia.
}

Publication history: Received on 26 August 2020; revised on 06 September 2020; accepted on 09 September 2020

Article DOI: https://doi.org/10.30574/wjarr.2020.7.3.0329

\begin{abstract}
Unlike past pandemics, the coronavirus has peculiarly surged worldwide with many countries adopting preventive measures suggested by the World Health Organization (WHO). However, levels of observance of these measures come with challenges that vary across countries, depending on the sociocultural environment. The Gambia, one of the smallest country in West Africa with a low-income economy experienced great challenges in the face of this pandemic in all sectors, especially in the healthcare systems, socio-cultural factors, education, trade and tourism sectors. Some of these challenges are difficulty to enforce social/physical distancing measures and lack of funds to adequately and properly institute quarantine. Strict enforcement of the state of emergency regulations and the continuous sensitization of individuals to be responsible for their health and wellness is one way of mitigating the spread of the virus. Additionally, seeking professional support, training, occupational health and safety, postponement of the payment of loans and interest, provision of tax breaks for tourism establishments and supporting public-private partnership in the establishment of a Gambian registered airline, are ways to minimize the impact of this and any future pandemic.
\end{abstract}

Keywords: COVID-19 pandemic; Healthcare; Education; The Gambia; Social/physical distancing; Socio-cultural environment.

\section{Introduction}

Once a while, in every century the world witness a disease pandemic. In the $21^{\text {st }}$ century in the year 2020 , the outbreak of the novel coronavirus disease (COVID-19) which has caused a huge burden to government healthcare systems, organizations, and individuals was first reported in December 2019 in Wuhan, China [1]. COVID-19 which is an acute respiratory pneumonia-like infection has been spreading rapidly all over the world and is recognized as a global health concern that has set global public health institutions on high alert [1, 2]. According to the World Health Organization (WHO) report, on 4th September 2020, globally, the total number of people diagnosed with COVID-19 was 26,121,999 cases, with 864, 618 deaths [3]. In Africa, the contagious COVID-19 infection crept in through travelers from Asia, Europe, and America. with its first COVID-19 case recorded in Egypt on 14 February, and, since then it has been spreading to a growing number of countries in the region with a total of 1,056,448 confirmed cases and 22,150 deaths, and among these, 3,150 confirmed cases and 99 deaths have been reported in The Gambia [3,4]. Currently, there is no vaccine and proven treatment for COVID-19 [5]. Therefore, as suggested by the WHO director-general, adopting strict preventive measures to avoid being exposed to the disease is highly recommended $[3,5]$. These include regular hand washing with soap and running water, use of face masks and social distancing now referred to as physical distancing to reflect the fact that people can still have social interactions with others while still maintaining measurable distance from others [6]. Additionally, several countries have instituted preventive regulations which allow people to work from

\footnotetext{
${ }^{*}$ Corresponding author: Tobiloba Oyejide Alex Omotosho

Department of Nursing and Reproductive Health, School of Medicine and Allied Health Sciences, University of the Gambia, Banjul Campus, The Gambia, PO Box 1646, Banjul
} 
home, banned international travels and mandatory lockdowns [6]. However, as these restrictive measures begin to ease up, there have been increases in the number of COVID-19 cases in many parts of the world [7]. The Gambia, a country with a fast growing population and a weak health care system [4,7], finds it challenging to cope with the impact of the pandemic. This article concisely looks at the challenges faced by COVID-19 pandemic in The Gambia and provides appropriate measures to curb the spread of the disease.

\section{The Gambia's response to COVID-19}

The Gambia registered its first confirmed case of COVID-19 on 17th March, 2020 [8]. This was an imported case from the United Kingdom. Upon arrival, the patient was isolated at the Medical Research Council Unit, The Gambia (MRCG), where treatment was given till recovery and discharged on 31st March, 2020 [8,9]. Like many countries around the world, The Gambia government initiated several strategies to control the spread of COVID-19, such as the establishment of a partial national lockdown for about four months, daily press briefings, continuous community sensitization via all media outlets, suspension of all public gatherings, contact tracing to confirmed cases, quarantines (e.g. isolation of travelers from hotspot countries), sample collections from high-risk contacts, mass screenings in certain locations, closure of all borders, fumigation, establishment of isolation/treatment centre(s) and COVID-19 national hotline(s), provision of psychosocial support to the affected and non-affected persons, deployment of newly hired health personnel to duty posts, and dispatch of security personnel to meet regional security needs [8-10]. These were supported by national and local coordination committees, surveillance, laboratory diagnostics, logistics/security, and communication $[8,9]$. In an attempt to provide basic medical supplies, several international organizations and development partners (World Bank, China, United Nations International Children's Emergency Fund (UNICEF), MRCG, and Jack Ma and Alibaba Foundations) and philanthropic individuals and institutions from home and abroad donated essential items (both in kind and in cash) in a bid to help the country fight against COVID-19 disease. The International Organization for Migration (IOM) helped in mainstreaming COVID-related activities into existing initiatives which comprised of the production of numerous protective suits and shoe coverings for the use of frontline immigration and border officials by some migrant returnees [11].

\section{Challenges of COVID-19 on The Gambia}

Upon report of the first confirmed COVID-19 case in the country, measures to curb the spread of the virus were laid out. The enforcement of these measures has had an immense impact on the Gambia's premier livelihood activities, economy and the people [11]. The Gross Domestic Product (GDP) of The Gambia relies heavily on Agriculture, Foreign aid and Tourism which is responsible for $22 \%$ of the 2018 GDP and creating $19 \%$ of total employment in The Gambia. With all tourism activities at a halt, individuals and the government have seen their purchasing powers disappear as uncertainty takes over [12]. For a country with a high poverty rate of $48 \%$ and ranking 174 out of 189 countries on the 2019 Human Development Index, the option to choose an efficient and complete lockdown is unlikely as the government lacks the resources to maintain the social safety net $[13,14]$. Moreover, with many still vulnerable to shocks, a crisis like COVID19 will move most of the vulnerable populations back into poverty while increasing vulnerability for others [14]. According to the United Nations Development Programme (UNDP), the Gambia is having an unemployment rate of 35.2 percent and with the COVID-19 outbreak creating an even more turbulent economic environment, many more people will enter unemployment and find it difficult to secure jobs [14]. Additionally, there are high illiteracy levels, chronic malnutrition, poor sanitation services, erratic water supply and most people living in an extended family setting which all exacerbate the spread of the virus. This explains why WHO recommendations such as social distancing and regular handwashing with soap and water may be a challenge for the Gambian populace [12-14]. To this end, challenges of COVID-19 to the healthcare systems, socio-cultural environment, education, tourism are further discussed.

\subsection{COVID-19 on The Gambia's healthcare systems}

The COVID-19 pandemic has revealed the fragility of many of the world's health systems forcing countries to make difficult choices on how to best contain the pandemic $[10,14]$.

The healthcare structure in The Gambia is characterized by three service delivery levels namely Primary, Secondary, and Tertiary. The primary healthcare focuses on villages with care delivered by village health workers and traditional birth attendants [14]. At the secondary healthcare level, care is provided by several health centres (both major and minor). The health centers are run by resident nurses, doctors, and ancillary staff. At the tertiary level, care is provided by four main referral hospitals including the main referral hospital in Banjul, Edward Francis Small Teaching Hospital (EFSTH) [11,13-14]. Two facilities that has the capacity for COVID-19 testing in the country are MRCG and the National Public Health Laboratories [9,14]. 
As a result of the isolation and quarantining of suspected Covid-19 cases, there was giving of false information about travel history and reluctance in visiting medical facilities for fear of being presumed as carriers of coronavirus [15].

The current Gambian government inherited a difficult campaign against Africa's foremost killer disease malaria. With the continuing threat from COVID-19, malaria has become the least priority in the national scale of medical preferences [16], prompting most people with complaints about symptoms of common diseases such as malaria, fever, common flu, and diabetes to prefer self-treatment at home and other places. In few cases, patients who reported mild illnesses are sent back home to avoid crowding and local transmission. In addition, elective surgeries, medical exams, routine outpatient medication reviews for hypertensive and diabetic patients are reduced to two days in a week and these are individuals most at risk of severe COVID-19 infection [15-17]. With the reported transmission of the virus among health workers, there is increasing scarcity of human resource and low motivation among healthcare workers [18]. Nurses threatened to halt service delivery if they did not benefit from monetary remunerations and provided with personal protective gears [18]. This has severe implications on the healthcare workforce and public as there has reportedly been a $50 \%$ increase in virus spread since the ease of lockdown $[13,18]$. Staff scaling was adopted to reduce the number of health care workers exposed to the virus. This step was necessitated by the lack of means of transportation as fares increased due to the lockdown. Bernard described similar occurrence in Zimbabwe but noted that staff scaling and Flexi hours by nurses compromised the effective screening, testing and possible management of COVID-19 cases [19].

\subsection{Socio-cultural environment in The Gambia}

The Gambia is a diverse multi-cultural society with many ethnic groups and the traditional emphasis on extended family as well as indigenous forms of celebration remain an integral part of everyday life of Gambians. Although there are known benefits and importance of physical distancing during the pandemic, many countries across the globe especially poor countries have struggled with implementing it [13,21-22]. In The Gambia, closely-knit family settings coupled with the widespread poverty makes it more challenging to institute social/physical distancing [20].

Social distancing or more accurately physical distancing which means keeping a safe space between oneself and other people who are not from your household is very important especially in the prevention of transmission most notably among people who are at higher risk (the elderly, other people with underlying medical conditions) for severe illness from COVID-19.21 Furthermore, maintaining physical distance of at least six feet or about two arms' length from other people helps to reduce exposure to contaminated respiratory droplets with indications that people who are infected but are asymptomatic can still spread the disease [20,21]. A commentary by the International Monetary Fund (IMF) on the outbreak's impact on Africa explained that social distancing was not realistic for the most vulnerable, and the idea of working from home was only possible for the few [23].

With one-third of the Gambian population living below the poverty line (57 percent mostly in rural areas) and with limited access to clean drinking water, most of the public still do not believe the presence of the virus within the country while others raised myths [23,24]. Some of these myths included high temperature which hinders the survival of the virus, drinking hot water, and eating garlic to kill the virus. Possible reasons for these include the seemingly insignificant number of deaths from COVID-19 in the country and as such most do not adhere to the preventive measures. Coupled with a lack of adequate time for the public to prepare and to reschedule their various social engagements, most people felt the enforcement of physical distancing would be an exercise in futility because the idea of telling people to stay at home was impossible [25]. People continued to meet in numbers at shops, and in public places like market squares, car parks and continue to give and receive handshakes [24,25]. Handshaking which has cultural underpinnings and is an ancient social norm for Gambians is seen as a sign of respect and many have defended its continuity during the pandemic by stating that whether you shake hands or not, it does not stop anyone getting infected [25]. One of the measures taken by the Government to minimize the risk of infections was decongesting overcrowded prisons. Several prisoners were granted presidential pardon and were expected to go into the communities where the practice of physical distancing is not followed thus defeating the purpose of the pardon [24,25]. One other measure used was self-quarantine of contacts which involves home isolation. Given the living arrangement in most homes, members of households often share facilities such as bathrooms, living space, bedrooms and within the community where the source of water is a community tap or borehole, such a measure will be difficult to practice [12,24-25]. Enforcement of physical/social distancing under these circumstances makes it impracticable in a low-income country like The Gambia.

\subsection{COVID-19 on The Gambia's education system}

The COVID-19 pandemic resulted in the upheavals of almost all sectors in The Gambia including the country's education sector. Schools at all levels have been closed resulting in disruption of student learning activities [26]. The pandemic has affected more than six thousand students across the country. The effect is that students will have fewer contact hours for the academic year 2019/2020 [14,24-26]. This has prompted The Gambia government through the Ministry 
of Education to find innovative ways such as the use of various media platforms to deliver lessons to students while staying at home $[14,26]$. For instance, the University of The Gambia (UTG) utilized Google online classroom to deliver lectures to students.

The Ministry of Basic and Secondary Education utilizes the radio and television to provide vital lessons to primary and secondary school students on essential subjects like Mathematics, English Language, Science, and Social Studies [26]. Despite these efforts by the government and educational institutions, many citizens were critical of this move citing that the method was a waste of resources. They argued that majority of students lack or have limited access to facilities such as televisions and radios, particularly those in rural areas [26,27]. Others argue that the e-learning methods do not give the students a chance to ask questions and/or raise concerns, and that the method does not cater for children with special needs while proponents of the method argue that it is the only alternative given the circumstances [27].

\subsection{COVID-19 on The Gambia's trade and tourism sectors}

The Gambia is heavily dependent on imports from abroad to sustain the economy with some of the main imports being fuel and oils, iron and steel, cereals, sugars, vehicles, and cement [14,26]. Within Africa, The Gambia's largest trade partner is Cote D'Ivoire especially with the importation of fuel products. Any decline or shortage in fuel will negatively affect other sectors such as agriculture, manufacturing and electricity generation [14,26]. Outside of Africa, The Gambia's largest trading partner is Europe consisting mainly of the United Kingdom and Spain. With Europe severely hit by the virus, a negative impact on trade both in terms of importation of goods and export earnings is expected [14,2628]. What this means for the country in a sharp rise in food prices at a time when many are expected to stay away from work, children are staying at home and there is the tendency to eat more while earning less. Many will also be forced to use up all their savings to meet up with family demands.

The Gambia is known for its tourist attraction which is seasonal for a period of six months (October to April) [14,29]. The Gambia Tourism Board stated that over 42,000 people benefit from direct employment in the industry. The sector suffered an external shock due to the 2014 Ebola crisis but rebounded in 2019, however, the advent of COVID-19 which has resulted in the closure of hotels, restaurants, and evacuation of tourists in the country during the tourist season has made the industry and the economy at large even more susceptible to greater revenue losses [28,29]. Many businesses such as travel agencies have also been affected and many people have lost their source of income as tourism is the largest foreign exchange earning for the country. Many youths who serve as escorts for tourists have seen their livelihoods taken away from them. Some of them have been redeployed to act as coronavirus guides for their local communities, raising awareness and explaining to their fellow Gambians how to prevent the spread of infection [29,30]. Less obvious consequences like a setback to poverty alleviation initiatives tied to tourism through youth and women's empowerment programmes could also be experienced [30].

\section{Probable solutions and recommendations}

At a point, The Gambia eased its lockdown but spikes in events caused recent adjustments to this decision [8]. More deaths have been recorded and all the seven health regions have reported cases of COVID-19 [8,31].

There is a need to hold security officials responsible for enforcing the still-ongoing state of emergency. There is still a need for the continued aggressive tracing of cases and contacts, strict quarantine, and screening, as well as education to promote good hand hygiene practices. It is also important that The Gambia government studies accurately and decide on the most suitable time for the opening of borders taking a leaf of countries that have begun to see a return of COVID19 after the reopening of their borders [31]. The government could perhaps first try to ensure that ongoing local transmissions are kept under great control and thereafter institute a self-swabbing test for anyone coming into the country [31].

While solutions to the disruption caused by COVID-19 to the education sector have been innovative and responsive, the reality remains that some schools and individuals are better positioned than others to benefit. The government needs to focus on professional support and training, occupational safety and health (OSH), employment and working conditions, and involvement in education responses [32]. The socio-emotional and mental health impacts of COVID-19 and the pandemic response measures on teachers, parents, and students - including anxiety, stress and feelings of uncertainty - have not been widely discussed, yet are as vital to OSH as protective equipment and social distancing, and must therefore be taken into account when developing OSH strategies [32].

Additional measures must be taken promptly, anticipating the potential challenge that would be faced by the hospitals in the case of an upsurge of COVID-19 cases. The Gambia should endeavor to support the preparedness of underserved 
areas. Enhancing surveillance for infectious diseases through rapid detection is very crucial to containing the spread and as well, enforcing the thorough application of infection prevention and control guidelines in health facilities, especially in the emergency departments and outpatient clinics is important as these serve as entry points for such infectious diseases [6,33]. The Government must source enough protective gear for the healthcare workers who will have to tackle COVID-19 patients in the frontline [6,32]. Measures need to be taken to keep the healthcare workforce motivated to face sudden and unexpected upsurge in cases. Training of physicians and nurses with expert help from developed nations could help with this [33]. The Gambia government should also put in more effort to assess the understanding of the general public at such times as this and engage more clinical experts to liaise with the media.

The government can develop a sustainable checklist of short and long term considerations to safeguard the tourism sector in the bid to move through the recovery phase while building prosperity and resilience. Short term considerations could involve embarking on projects that involve job creation, which gives a boost to economic activity and that generates stimulus and employment benefits [33]. The government can request for commercial banks to allow for a postponement on the payment of loans and interest, provide tax breaks for tourism establishments to smoothen rebound and support with the payment of employees who are laid off $[28,33]$. Long term considerations could include projects that will improve the country's resilience to future shock. This could involve supporting public-private partnership in the establishment of a Gambian registered airline, a shift of direction in spending more on product development than marketing as well as modifying and repackaging of the seasonality of tourist attractions [28,31-34].

Policymakers have a lot of work to do at the moment and as governments shift their focus to recovery and rebuilding, the choices made will determine what sort of future we will have and how strong we will be as a nation to confront and manage any future global crises.

\section{Conclusion}

The world is still on the steep learning curve about the virus, and it could take a couple of years to work things out. So far, the challenges posed by this pandemic on The Gambia's socio-culture, health care, education, trade, and tourism sectors have created overwhelming national stress. Therefore, caution needs to be taken and measures to improve the country's ability to respond to outbreaks need to be worked upon. The government has to ensure that health awareness through the media is more aggressive and the public's responsibility to adhere to strict regulations in line with the ongoing state of emergency is adequately followed. As efforts to curb the spike in the virus transmission are instituted, it will be interesting to see how well the government drives its people towards national and individual balance and satisfaction.

\section{Compliance with ethical standards}

\section{Acknowledgments}

Appreciation goes to Dr. Thomas Senghore, Senior Lecturer, Department of Nursing and Reproductive Health, School of Medicine and Allied Health Sciences, University of the Gambia for his technical support.

\section{Disclosure of conflict of interest}

The authors declare that they have no conflict of interest. No commercial organization with a direct or indirect interest in the content of this study has conferred or will confer a benefit on the authors or any organization with which the authors are associated. This study has not previously been presented in any form.

\section{References}

[1] WHO. (2020). Emergencies, preparedness, response: novel coronavirus-China.

[2] Legido-Quigley H, Asgari N, Teo Y, et al. (2020). Are high-performing health systems resilient against the COVID19 epidemic? Lancet, 395(10227).

[3] WHO. (2020). Coronavirus disease (COVID-19) - weekly epidemiological update, 1-3.

[4] Ministry of Health. (2020). The Gambia COVID-19 outbreak situational report -136, 1-5.

[5] Bao Y, Sun Y, Meng S, Shi J and Lu L. (2020). 2019-nCoV epidemic: address mental health care to empower society. Lancet, 395(110224), 37-38. 
[6] Anwar S, Nasrullah M and Hosen MJ. (2020). COVID-19 and Bangladesh: challenges and how to address them. Front. Public Health, 8(154), 1-8.

[7] Braine T. (2020). Coronavirus cases spike in Texas, Arizona, Florida after reopening.

[8] Ministry of Health. The Gambia COVID-19 outbreak situational report -88, 4-5.

[9] MRCG. (2020). Confirmed case of COVID-19 in The Gambia.

[10] WHO. (2020). WHO Africa/Gambia receives support to contain spread of COVID-19. Geneva, Switzerland.

[11] Reliefweb. (2020). Gambian returnees produce protective equipment for COVID-19 frontline border officials, The Gambia.

[12] Sallah FB. (2020). The Gambia's response to COVID-19: socio-economic and human rights implications. The Chronicle. Banjul, The Gambia.

[13] Mussa S. (2020). COVID-19 in the 3rd republic. The Chronicle. Banjul, The Gambia.

[14] UNDP. (2020). Update on the socio-economic situation following covid-19 outbreak in The Gambia Banjul, The Gambia, 1-3.

[15] AP Anews. (2020). Gambia: hospitals bare as covid-19 stigma simmers. Banjul, The Gambia.

[16] Grover A. (2020). Long-term impact of COVID-19 pandemic on healthcare scenario in India.

[17] United Nations. (2020). COVID-19 highlights nurses' vulnerability as backbone to health services worldwide.

[18] Jeffeng K. (2020). Gambia COVID-19 frontline workers strike over unpaid allowances. The Chronicle. Banjul, The Gambia.

[19] Bernard N. (2020) A reflection on the implementation on flexi-working hours on public health service delivery during coronavirus (COVID-19) era in Zimbabwe: the survey for the nursing professional employed at Parirenyatwa group of hospitals. Int. J. Adv. Res, 8(5), 893-904.

[20] Drammeh BM. (2020). Gambia is not an island. The Chronicle. Banjul, The Gambia.

[21] CDC. (2020). Guidance and tips for tribal community living during COVID-19. Georgia, USA.

[22] Maxmen A. (2020). How poorer countries are scrambling to prevent a coronavirus disaster. Nature, 580, 173 174.

[23] Akwagyiram A and Toyana M. (2020). Africa's lockdowns sacrifices informal traders to save lives. South Africa.

[24] Loum P. (2020). Social distancing in Africa: Practical or unrealistic. The Chronicle. Banjul, The Gambia.

[25] APAnews. (2020). Social distancing? Some Gambians not amused.

[26] UNICEF. (2020). Corona virus (covid-19): our response. Banjul, The Gambia.

[27] Agence de Presse Africaine. (2020). Gambia adopts media schooling for basic education amid COVID-19.

[28] Nyang ST. (2020). Can Gambian tourism survive after COVID-19 pandemic? Serrekunda, KMC, The Gambia.

[29] UNDP. (2020). The tourism sector in the context of COVID-19 outbreak in The Gambia. Banjul, The Gambia, 4-6.

[30] Bah A and Stanford D. (2020). How Kenya and The Gambia are reshaping tourism after lockdown. World Economic Forum.

[31] Mumbai. (2020). COVID-19: Europe reopens border, China records second wave of case. Bandra East, India.

[32] International Labour Organisation. (2020). COVID-19 and the education sector. ILO; Geneva, Switzerland.

[33] Hammer $S$ and Hallegatte S. (2020). Planning for the economic recovery from COVID-19: a sustainability checklist for policymakers. The World Bank group. Washington DC, USA.

[34] Moli E. (2020). Partnership to assist tourism employees impacted by COVID-19 [Internet]. UNDP-Pacific Office. Suva, Fiji. 


\section{Author's short biography (optional)}

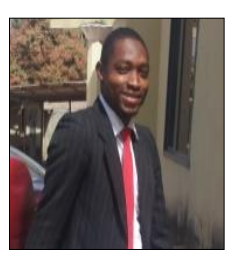

Tobiloba Oyejide Alex Omotosho

Tobiloba Oyejide Alex Omotosho is a nurse by profession and also a graduate assistant at the Department of Nursing and Reproductive Health, School of Medicine and Allied Health Sciences, University of the Gambia. He holds a Bachelor of Science degree in Nursing and Reproductive Health obtained at the University of the Gambia in 2016 and is currently undergoing a master's degree in Community Health Nursing with the same institution. His research interests are in the areas of public health, epidemiology, control of communicable and non-communicable diseases, women's health and chronic disease management.

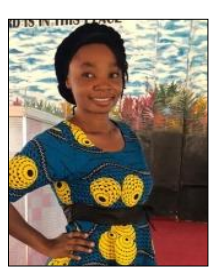

\section{Oluwatomilayo Felicity Omotosho}

Oluwatomilayo Felicity Omotosho is a nurse by profession and also a graduate assistant at the Department of Nursing and Reproductive Health, School of Medicine and Allied Health Sciences, University of the Gambia. She holds a Bachelor of Science degree in Nursing and Reproductive Health obtained at the University of the Gambia in 2016 and is currently undergoing a master's degree in Community Health Nursing with the same institution. Her research interests are in the areas of global/community health, demography and health, pediatric nursing, Infectious disease management and chronic disease management.

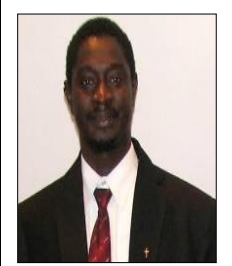

\section{Paul Bass}

Dr. Paul had his public health training at the Gambia College, University of the Gambia and College of Public Health, Taipei Medical University with concentrations in injury prevention \& control and environmental \& occupational health. He is currently a senior lecturer at the Department of Public \& Environmental Health, University of The Gambia. I successfully coordinated the project on the establishment of the trauma registries in two major hospitals in the Greater Banjul Area with funding support from the Injury Research Center at the University of Iowa and World Bank Global Facility small grants. I also served as an administrative officer for the National Institutes of Health/Fogarty International Center-funded project on Global Environment and Occupational Health (GEOHealth) on identifying needs and opportunities of occupational and environmental health risk factors in West Africa.

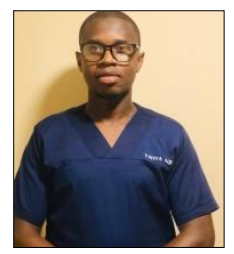

\section{Yahya Njie}

Yahya Njie is a nursing officer at the Edward Francis Small Teaching Hospital, The Gambia. He had his undergraduate nursing training at the University of the Gambia, The Gambia where he obtained a Bachelor of Science in Nursing degree in 2017. He is among the frontline healthcare workers fighting the COVID-19 in The Gambia under the case management team at the National COVID Treatment Center, Banjul. His research interests are in the areas of infectious disease management, public health, and qualitative research methodology. 